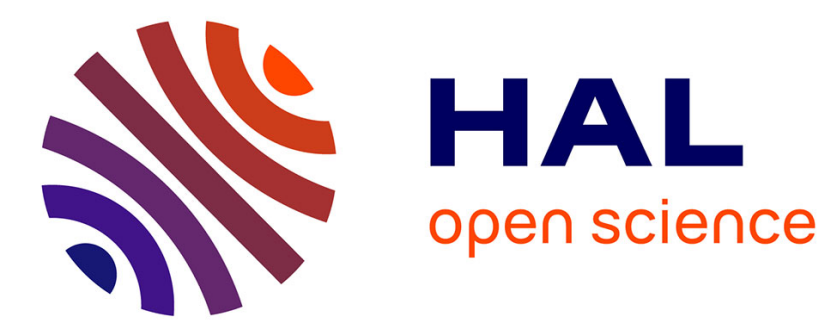

\title{
A new device to study isoload eccentric exercise
}

Gaël Guilhem, Christophe Cornu, Antoine Nordez, Arnaud Guével

\section{To cite this version:}

Gaël Guilhem, Christophe Cornu, Antoine Nordez, Arnaud Guével. A new device to study isoload eccentric exercise. Journal of Strength and Conditioning Research, 2010, 24 (2), pp.3476 - 3483. 10.1519/JSC.0b013e3181d640ec . hal-01566256

\section{HAL Id: hal-01566256 https://hal-insep.archives-ouvertes.fr/hal-01566256}

Submitted on 20 Jul 2017

HAL is a multi-disciplinary open access archive for the deposit and dissemination of scientific research documents, whether they are published or not. The documents may come from teaching and research institutions in France or abroad, or from public or private research centers.
L'archive ouverte pluridisciplinaire HAL, est destinée au dépôt et à la diffusion de documents scientifiques de niveau recherche, publiés ou non, émanant des établissements d'enseignement et de recherche français ou étrangers, des laboratoires publics ou privés. 


\title{
A New Device to Study IsOLOAD ECCENTRIC ExERCISE
}

\author{
Gaël Guilhem, Christophe Cornu, Antoine Nordez, and Arnaud Guével \\ "Motivity, Interactions, Performance" Laboratory, Faculty of Sport Sciences, University of Nantes, Nantes, France
}

\section{Abstract}

Guilhem, G, Cornu, C, Nordez, A, and Guével, A. A new device to study isoload eccentric exercise. $J$ Strength Cond Res 24(X): 000-000, 2010-This study was designed to develop a new device allowing mechanical analysis of eccentric exercise against a constant load, with a view in mind to compare isoload (IL) and isokinetic (IK) eccentric exercises. A plate-loaded resistance training device was integrated to an IK dynamometer, to perform the acquisition of mechanical parameters (i.e., external torque, angular velocity). To determine the muscular torque produced by the subject, load torque was experimentally measured ( $\left.T_{\text {Lexp }}\right)$ at 11 different loads from $30^{\circ}$ to $90^{\circ}$ angle $\left(0^{\circ}=\right.$ lever arm in horizontal position). $T_{\text {Lexp }}$ was modeled to take friction effect and torque variations into account. Validity of modeled load torque $\left(T_{\llcorner\operatorname{Lod}}\right)$ was tested by determining the root mean square (RMS) error, bias, and $2 S D$ between the descending part of $T_{\text {Lexp }}$ (from $30^{\circ}$ to $90^{\circ}$ ) and $T_{\text {Lmod. }}$ Validity of $T_{\text {Lexp }}$ was tested by a linear regression and a Passing-Bablok regression. A pilot analysis on 10 subjects was performed to determine the contribution of the torque because of the moment of inertia to the amount of external work (W). Results showed the validity of $T_{\text {Lmod }}$ (bias $=0 \%$; RMS error $=$ $0.51 \%$ ) and $T_{\text {Lexp }} S E M=4.1 \mathrm{~N} \cdot \mathrm{m}$; Intraclass correlation coefficient $(I C C)=1.00$; slope $=0.99 ; y$-intercept $=20.13$ ). External work calculation showed a satisfactory reproducibility ( $S E M=38.3 \mathrm{~J} ; I C C=0.98$ ) and moment of inertia contribution to $\mathrm{W}$ showed a low value (3.2 $62.0 \%$ ). Results allow us to validate the new device developed in this study. Such a device could be used in future work to study IL eccentric exercise and to compare the effect of IL and IK eccentric exercises in standardized conditions.

KEY WoRDS constant load, lengthening contraction, ergometer, knee extensors, muscular torque

Address correspondence to Arnaud Guével, arnaud.guevel@univnantes.fr.
INTRODUCTION

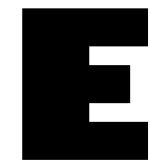

ccentric exercise involves muscular contractions against a load higher than the torque exerted by the activated muscular group. The mechanical load applied to the mobilized segment during eccentric exercise involves stretching of elastic components of muscle - tendon complex that absorbs mechanical energy. This energy is dissipated as heat or stored as elastic recoil potential energy, and that can subsequently be recovered. Such a mechanical behavior leads to the production of high muscular force levels that can induce some muscular damages (25). To protect the contractile structures against these high tension levels, the neuromuscular system uses neural regulatory mechanisms at the spinal level (e.g., presynaptic inhibition of group Ia muscle spindle afferents, homosynaptic postactivation depression [13]) that limits the recruitment or discharge rate of motor units (14). These mechanical and neural specific responses to eccentric exercise led some authors to study its effects in rehabilitation protocols to restore neuromuscular function (11) or in training sessions to improve the muscular force production (24).

Eccentric exercise is often performed against a constant external resistance (isoload, IL) $(8,19)$. During such a task, movement velocity is variable, and the muscles are mainly loaded at flexed and extended joint angles. Although the terms IL or isoinertial actions more accurately reflect weight loading actions $(2,8)$, these kinds of tasks are often termed isotonic movements in the literature (15). Eccentric exercises can also be performed at a constant velocity (23) on an isokinetic (IK) dynamometer. In IK movements, subjects have to overcome an accommodating resistance adapted to the muscle torque subjects are able to exert, thus leading to a constant movement velocity. Isokinetic mode is consequently supposed to maximally load the muscles through the overall range of motion and to produce of higher peak torque than the IL mode. These differences in torque and movement velocity may induce different responses and adaptations of the neuromuscular and musculoskeletal systems. Numerous studies have investigated the effect of IK $(16,18,24)$ or IL $(19,29,36)$ eccentric training on the neuromuscular system, without comparing the specific adaptations induced by these 2 eccentric exercise modes. Isoload eccentric exercise is performed on plate-loaded resistance training devices or with weightlifting bars and dumbbells, whereas IK eccentric 
exercise is realized on IK dynamometers. Considering the lack of standardization of mechanical parameters (e.g., movement velocity, amount of external work), comparison of these 2 exercise modes is consequently difficult to complete. Previous studies conducted on concentric exercise showed that mechanical differences in mechanical load in the IL and IK modes could induce some specific neural responses $(30,32,33)$. Thus, it could be interesting to characterize the response of neuromuscular system to IL and IK eccentric exercises in standardized conditions. Such a study requires a device allowing acquisition of mechanical parameters in both modes to develop a standardization methodology of the amount of external work and the angular velocity (31).

Isokinetic dynamometers (e.g., Biodex, Shirley, NY, USA; Cybex, Medway, MA, USA; Kin-Com, Chattanooga, TN, USA) do not allow performing eccentric exercise in IL mode. Therefore, we customized an IK dynamometer to perform acquisition of mechanical parameters such as muscular torque, joint angle, and angular velocity during IL eccentric exercise. This device was designed to measure the amount of external work performed and the angular velocity on the whole range of motion during both IL and IK exercise modes using the same ergometer. The aim of the present study was to test the validity of mechanical measurements performed by this customized device.

\section{Methods}

\section{Experimental Approach to the Problem}

The aim of this study was to develop a simple device to study eccentric exercise in the IL mode on the same ergometer that is commonly used in the IK mode. For this purpose, we added a system of guided loads to an IK dynamometer Biodex System 3 Pro (Biodex ${ }^{\circledR}$ Medical Systems, Shirley, NY, USA) to elicit the conditions of weightlifting (IL) exercise. This device was used to elicit lengthening contractions of knee extensor muscles against a constant load and measure the amount of external work and angular velocity in this exercise mode. External work (W) is calculated as the area under the muscular torque - angle relationship. In the IK mode, muscular torque is directly measured by the dynamometer. In the IL mode, the muscular torque exerted during eccentric contractions is produced against a load torque. Consequently, the torque measured by the dynamometer in the present study required a mathematical correction. Each torque applied on the dynamometer attachment was determined to calculate the muscular torque produced during eccentric

accuracy and reproducibility of external work calculation.

\section{Subjects}

Ten male sport sciences students (age $=2163$ years; height $=$ $18066 \mathrm{~cm}$; and body mass $=7869 \mathrm{~kg}$ ) volunteered to participate in this study. All students were moderately active (daily sport activities $=1.461 .0$ hours), nonspecific of a physical activity, and refrained from participating in a resistance training program for the duration of the study. Subjects were informed of risk and discomfort associated with the experimental procedures before they gave their written consent to participate. The study was approved by the local ethics committee and was conducted in accordance with the Declaration of Helsinki (1964 revised in 2001).

\section{Procedures}

Device Description. A specific module was integrated to the IK dynamometer to elicit IL eccentric exercise. This module was comprised by a plate-loaded resistance training device, a wire and a half-circle metal piece. The diameter of the half circle was equal to $0.395 \mathrm{~m}$ to be large enough for applying sufficient torque levels in eccentric exercise and small enough to be adjustable to the subjects with the smallest leg. Loads were anchored to the wire, which crossed 2 pulleys and followed the half-circle piece fixed to the lever arm, to maintain a constant applied torque on the whole range of motion $\left(30-90^{\circ}, 0^{\circ}=\right.$ lever arm in horizontal position) (Figure 1). In the return phase, the load was automatically pulled up by the motor of the dynamometer to the starting position $\left(30^{\circ}\right)$ at a constant angular velocity $\left(30^{\circ} \cdot \mathrm{s}\right)$ to ensure the subject performed eccentric-only exercise, without any intervention of the investigator or the subject during the return phase. Mechanical signals of the dynamometer (i.e., angle, torque and angular velocity) were recorded at a sampling frequency of $1,000 \mathrm{~Hz}$.

External Work Calculation. Eccentric exercise produces negative work, involved in braking actions (i.e., jump landing, downhill running, and stairs descent) (12). The amount of external angular work $(W)$ is calculated at each time interval

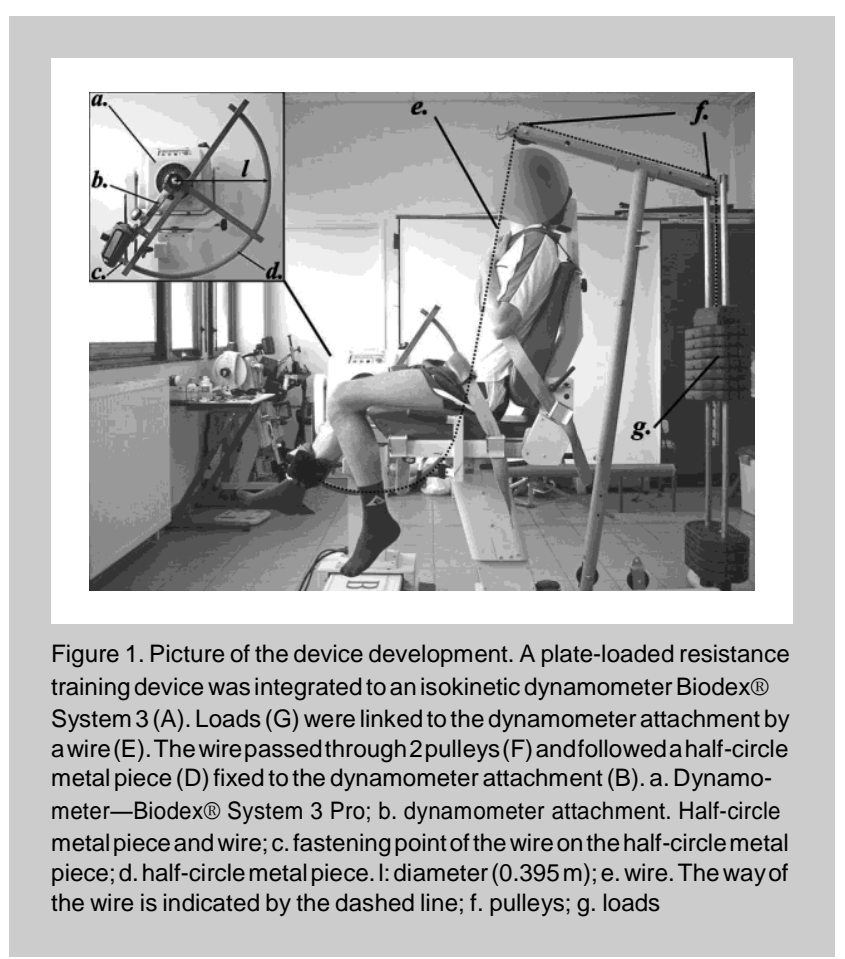


from the muscular torque produced by the subject $\left(T_{\text {mus }}\right)$ and the angular position $(\mathbf{u}), \underset{\mathrm{Z}^{\mathrm{u}_{n}}}{\exp } \operatorname{messed}$ by equation 1 :

$$
W 1 / 4 \quad T_{\text {mus }} \mathbf{u d u} \text {; }
$$

where $W$ is the external work $(\mathrm{J}), T_{\text {mus }}$, the muscular torque $(\mathrm{N} \cdot \mathrm{m})$, and $\mathbf{u}$ is the angle $(\mathrm{rad})$.

Subjects produced a muscular torque $\left(T_{\text {mus }}\right)$ in IL eccentric knee flexions opposing the load torque $\left(T_{\mathrm{L}}\right)$, the attachment torque (the lever arm and the half-circle piece, $T_{a}$ ), and the torque created by the subject' $\mathrm{s}$ leg and foot combined $\left(T_{\text {leg }}\right)$. Consequently, the determination of $T_{\text {mus }}$ required the calculation of each one of the torques involved in IL eccentric exercise. According to the fundamental principle of dynamics, the torque balance existing on the dynamometer attachment in IL eccentric exercise is presented by equation 2 :

$$
T_{\text {mus }} 1 / 4-T_{\text {mes }} \mathbf{p} T_{\text {a }} \mathbf{p} T_{\text {leg }} \mathbf{p} T_{\mathrm{L}} \mathbf{p} J \epsilon_{\mathbf{u}}
$$

where $T_{\text {mus }}$ is the muscular torque $(\mathrm{N} \cdot \mathrm{m}) ; T_{\mathrm{a}}$, the attachment torque $(\mathrm{N} \cdot \mathrm{m}) ; T_{\text {leg }}$, the leg torque $(\mathrm{N} \cdot \mathrm{m}) ; T_{\mathrm{L}}$, the load torque $(\mathrm{N} \cdot \mathrm{m})$; J, the mass moment of inertia $\left(\mathrm{kg} \cdot \mathrm{m}^{2}\right)$; $\mathrm{u}$, the angular acceleration of the lever $\operatorname{arm}\left(\operatorname{rad} \cdot \mathrm{s}^{22}\right)$; and $T_{\text {mes }}$ is the measured torque $(\mathrm{N} \cdot \mathrm{m})$.

To calculate $T_{\text {mus }}$, each component of equation 2 was determined. $T_{\text {mes }}$ was directly measured by the dynamometer. $T_{\mathrm{a}}$ and $T_{\operatorname{leg}}$ were measured at a fixed knee angle $\left(30^{\circ}\right)$ and calculated on the whole range of motion (1). The methods used to assess $T_{\mathrm{L}}$ and $J \mathbb{U} \in$ are described below.

Load Torque $\left(\mathrm{T}_{\mathrm{L}}\right)$ Calculation. Eleven different loads ( 0 then 196 - 687N, every 49N) were applied on the lever arm without subject, from $30^{\circ}$ to $90^{\circ}$ with the dynamometer set in passive mode (angular velocity $=1^{\circ} \cdot \mathrm{s}^{21}$ ) to measure the experimental load torque $\left(T_{\text {Lexp }}\right)$ given by the dynamometer. Theoretically, the torque applied by the loads on the lever arm is calculated by equation 3 :

$$
T_{\text {Lth }} 1 / 4 m g l
$$

where $T_{\mathrm{Lth}}$ is the theoretical load torque $(\mathrm{N} \cdot \mathrm{m}) ; m$, the load mass $(\mathrm{kg}) ; g$ is in $\mathrm{m} \cdot \mathrm{s}^{22}$; and $l$ is the lever arm length(m).

Although experimental load torque measurements were close to the theoretical load torque, we identified (a) a friction effect and (b) variations of torque because of the imperfect rolling contact between the wire and the metal piece that exists on every plate-loaded resistance device, as illustrated in Figure 2. Consequently, equation 3 could not be used to accurately determine the torque applied by the load. Thus, descending phase (from $30^{\circ}$ to $90^{\circ}$ angle) of the $T_{\text {Lexp }}-$ angle load 3-dimensional relationship was modeled by a surface model as a $T_{\text {Lmod }}$ - angle - load relationship (linear increase with torque and a second-degree polynomial model with angle, Figure 3) so that load - torque variations were taken into account. $T_{\text {Lexp }}$ was also measured twice a week between the 2 measurements, to ensure there was no drift in the error value between $T_{\text {Lmod }}$ and $T_{\text {Lexp. }}$.

Mass Moment of Inertia Calculation. As shown by equation 2, the determination of $T_{\text {mus }}$ requires the calculation of the torque because of the mass moment of inertia (J山F). In IL eccentric exercise, the moment of inertia of the system $(J)$ is calculated according to equation 4 :

$$
\begin{array}{cc}
J 1 / 4 J_{\text {a }} \mathbf{p} J_{\operatorname{leg}_{2}} \mathbf{p} J_{\mathrm{L}} ; & \partial 4 \mathrm{P} \\
J_{\mathrm{L}} 1 / 4 \mathrm{ml}^{\prime} ; & \partial 5 \mathrm{P}
\end{array}
$$

where $J$ is the system moment of inertia $\left(\mathrm{kg} \cdot \mathrm{m}^{2}\right)$; $J_{\mathrm{a}}$, the attachment moment of inertia $\left(\mathrm{kg} \cdot \mathrm{m}^{2}\right) ; J_{\text {leg }}$, the leg moment

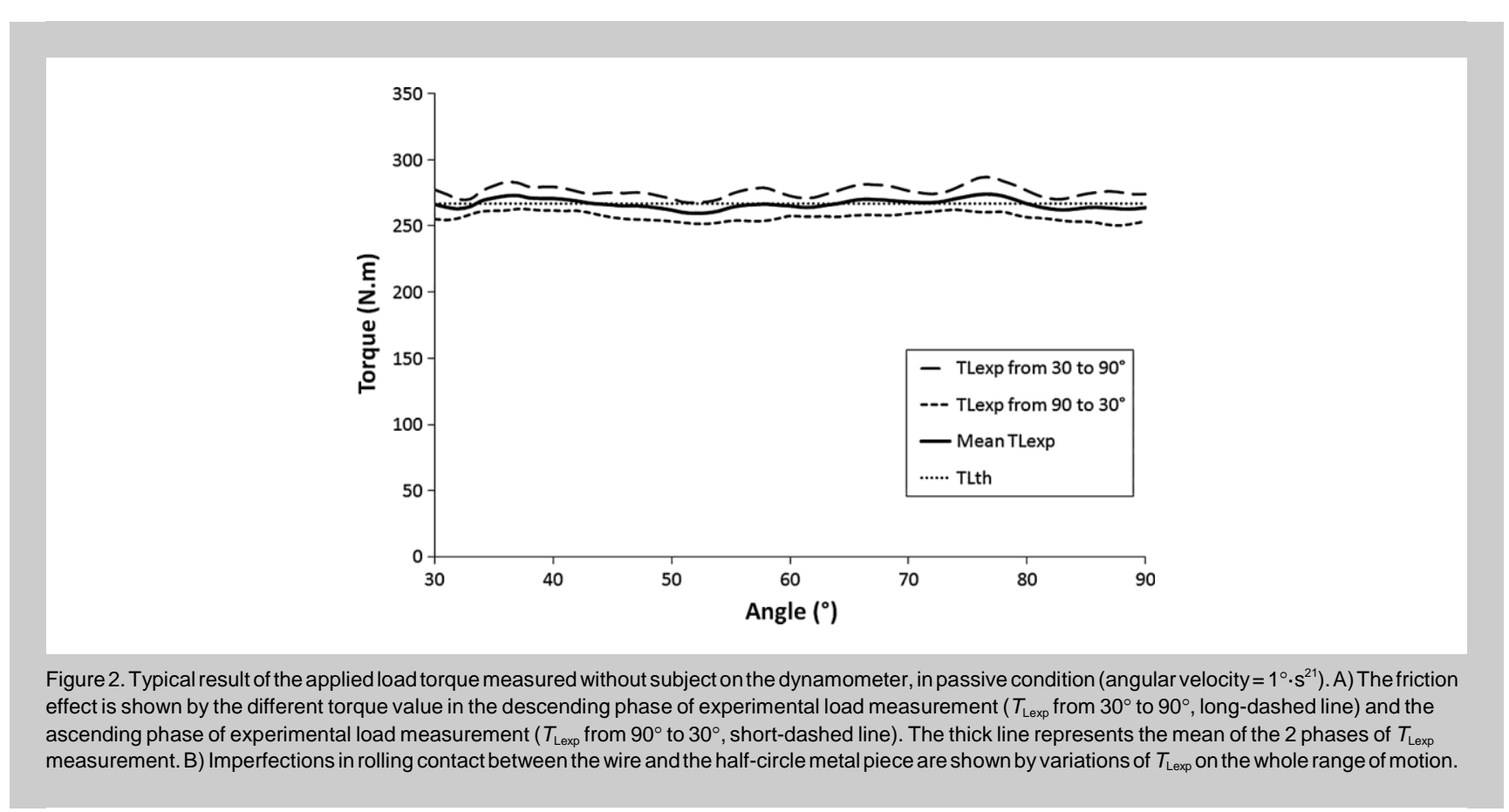



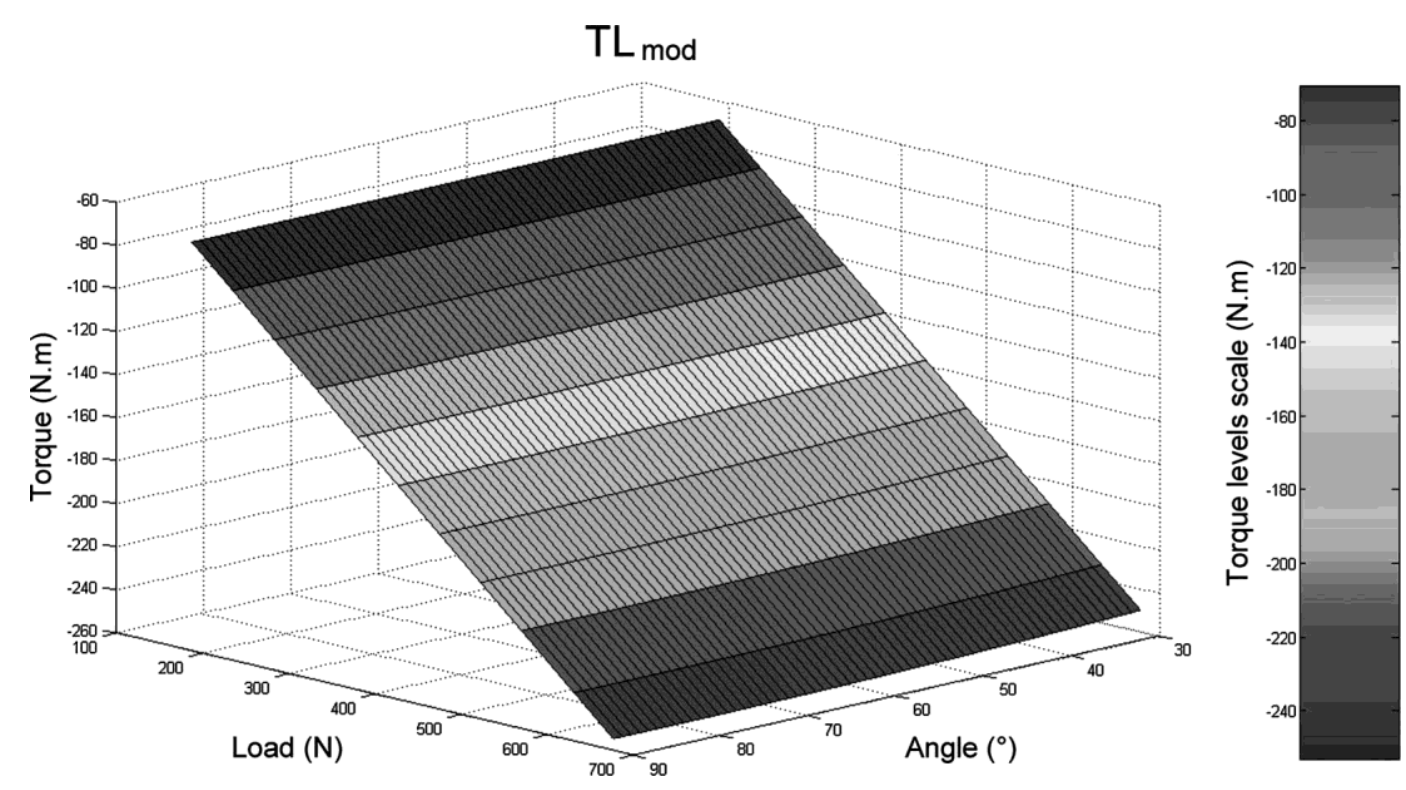

Figure 3. Graphical representation of the 3-dimensional relationship between modeled load torque $\left(T_{\mathrm{Lmod}}, \mathrm{N} \cdot \mathrm{m}\right)$, the angle $\left(^{\circ}\right)$ and the applied load $(\mathrm{N})$, on the overall range of motion (from $30^{\circ}$ to $90^{\circ}, 0^{\circ}=$ lever arm in horizontal position). The colored-scale (on the right) indicates the level of load torque from the lowest values (blue color) to the highest values (red color).

of inertia $\left(\mathrm{kg} \cdot \mathrm{m}^{2}\right)$; $J_{\mathrm{L}}$, the load moment of inertia $\left(\mathrm{kg} \cdot \mathrm{m}^{2}\right)$; $m$, the load mass $(\mathrm{kg})$; and $l$ is the radius of gyration $(\mathrm{m})$

A pilot analysis showed that the mean angular acceleration (uf) in IL eccentric flexion was equal to $0.01 \mathrm{rad} \cdot \mathrm{s}^{22}$, suggesting a low contribution of the torque because of the moment of inertia to the amount of external work. Therefore, we hypothesized that the contribution of $J_{\text {leg }}$ and $J_{\mathrm{a}}$ could be considered as negligible. To estimate the maximal contribution of $J_{\mathrm{a}}$ and $J_{\operatorname{leg}}$ to the total moment of inertia, $J_{\mathrm{L}}$ was calculated, as the mass multiplied by the squared radius of gyration $(0.395 \mathrm{~m})$, for the lowest load used by the subjects (38 $\mathrm{kg}$ ). Minimal value of $J_{\mathrm{L}}$ was equal to $5.929 \mathrm{~kg} \cdot \mathrm{m}^{2}$. The segmental moment of inertia depends on the anthropometrical characteristics of the subjects. According to the table established by Zatsiorsky and Aktov (37), the mean segmental moment of inertia of a man' $\mathrm{s}$ leg $\left(J_{\text {leg }}\right)$ is about

a total contribution of $J_{\text {leg }}$ and $J_{\mathrm{a}}$ about $0.669 \mathrm{~kg} \cdot \mathrm{m}^{22}$. Consequently, the maximal contribution of $J_{\mathrm{a}}$ and $J_{\operatorname{leg}}$ to $J$ is estimated to about $10 \%$.

To test the hypothesis that this low contribution (10\%) can be considered as negligible, the moment of inertia contribution to the amount of external work was determined during an ILeccentric session. During afamiliarization session, subjects get used to the customized dynamometer and their maximal repetition was determined (1RM). One repetition maximum corresponded to the maximal load that subjects were able to mobilize only one time on the whole range of motion $\left(90-30^{\circ}\right)$. One week later, subjects performed a test session consisting ofa 5-minute warm-up on a cycloergometer, a specific warm-up on the dynamometer, and 1 set of 8 lengthening contractions of knee extensors of their dominant leg (the one used to kick a ball, all subjects were right-leg dominant) in the IL mode, at $120 \%$ of their 1RM. The amount of external work was calculated by the numerical integration of the $T_{\text {mus }}$ - angle relationship (see External work calculation). Thereafter, the moment of inertia contribution to the amount of external work was determined. One week later, subjects

TABLE 1. Comparison between $T_{\text {lexp }}$ and $T_{\text {Lmod }}{ }^{*}{ }_{\dagger}$

\begin{tabular}{lrr}
\hline & Row value $(\mathrm{N} \cdot \mathrm{m})$ & Relative value \\
\hline & & \\
Bias & 0.0 & 0.0 \\
RMS error & 1.6 & 0.5 \\
Max error & 3.2 & 1.0 \\
Min error & 23.5 & 21.1 \\
$2 S D$ & 1.6 & 0.5 \\
\hline
\end{tabular}

${ }^{*} \mathrm{RMS}$ error = root mean square error; Max error = maximum error; Min error $=$ minimum error; $T_{\operatorname{Lexp}}=$ experimental load torque; $T_{\operatorname{Lmod}}=$ modeled load torque.

† Bias, RMS error, Max error, Min error, and 2SDs between $T_{\text {Lexp }}$ and $T_{\text {Lmod }}$ expressed in row and relative value (as a percentage of mean). 
performed a second test session identical to the first test session previously described. The time interval between test sessions was chosen to ensure a complete strength recovery before the second test session (26).

\section{Statistical Analyses}

To determine the error between the load torque measurement and the modeled load torque $\left(T_{\text {Lmod }}\right)$, Root mean square (RMS) error, bias, and $2 S D_{\mathrm{s}}$ between $T_{\text {Lexp }}\left(\right.$ from $30-90^{\circ}$ ) and $T_{\text {Lmod }}$ were calculated for each applied load.

Validity of load torque measurement was determined by the calculation of the Bravais - Pearson correlation coefficient $(r)$, slope and $y$-intercept of the linear regression, SEM, intraclass correlation coefficient (ICC), and coefficient of variation (CV) between $T_{\text {Lth }}$ and $T_{\text {Lexp }}$ (17). The power of this method to assess the validity of a measurement is discussed further in the literature $(3,6,7)$. Thus, a Passing - Bablok regression (5) was also performed using Medcalc Software ${ }^{\circledR}$ (Mariakerke, Belgium). This method determines the slope and the $y$ intercept of linear regressions with a $95 \%$ confidence interval (95\% CI). A significant difference between the 2 measurements is found if ' "1.0' ' for the slope and/or ' ' 0 ' ' for the $y$-intercept are not included in the 95\% CI. As stated above, a friction effect was noticed during $T_{\text {Lexp }}$ measurements (Figure 2). Consequently, to determine the validity of $T_{\text {Lexp }}$, a linear regression between the mean of the ascending phase (from $90^{\circ}$ to $30^{\circ}$ ) and the descending phase (from $30^{\circ}$ to $90^{\circ}$ ) of $T_{\text {Lexp }}$, and $T_{\text {Lth }}$ was performed.
Trial-to-trial reproducibility of amount of external work between both identical test sessions was determined by the calculation of the ICC, SEM, and the CV (17). The critical level of significance was set at $p \# 0.05$.

\section{RESUlts}

\section{Validity Lf Lod $_{\text {Lad Torque }}$}

The Lmod $^{-}$load-angle 3-dimensional relationship is psq sented in Figure 3. Root mean square error, bias, and 2 between $T_{\text {Lexp }}$ and $T_{\text {Lmod }}$ are presented in Table 1. Results showed the validity of $T_{\mathrm{Lmod}}$ with a bias equal to zero and an RMS error less than $1 \%$ of the mean of $T_{\text {Lexp }}$ and $T_{\text {Lmod. }}$.

Results concerning the validity of $T_{\text {Lexp }}$ measurements showed satisfactory values of $S E M(4.1 \mathrm{~N} \cdot \mathrm{m}), \operatorname{ICC}(1.00)$, and CV (6.0\%) between $T_{\text {Lexp }}$ and $T_{\text {Lth }}$ (34). Linear regression showed a $y$-intercept close to zero and a slope slightly lower than 1.00 (Figure 4). These results were confirmed by the Passing - Bablok regression that did not show any significant difference between the mean of $T_{\text {Lexp }}$ and $T_{\text {Lth }}$ (Figure 4).

Calculation of the Torque because of the Moment of Inertia The mean contribution of the torque because of the moment of inertiareached $3.262 .0 \%(0.8-6.7 \%)$ of the totalamount of work performed by the subjects in the IL eccentric set. Contribution of leg and attachment moment of inertia was about $10 \%$ of total moment of inertia. Leg and attachment moment of inertia contribution to the amount of external work was consequently less than $0.5 \%$. Therefore, in

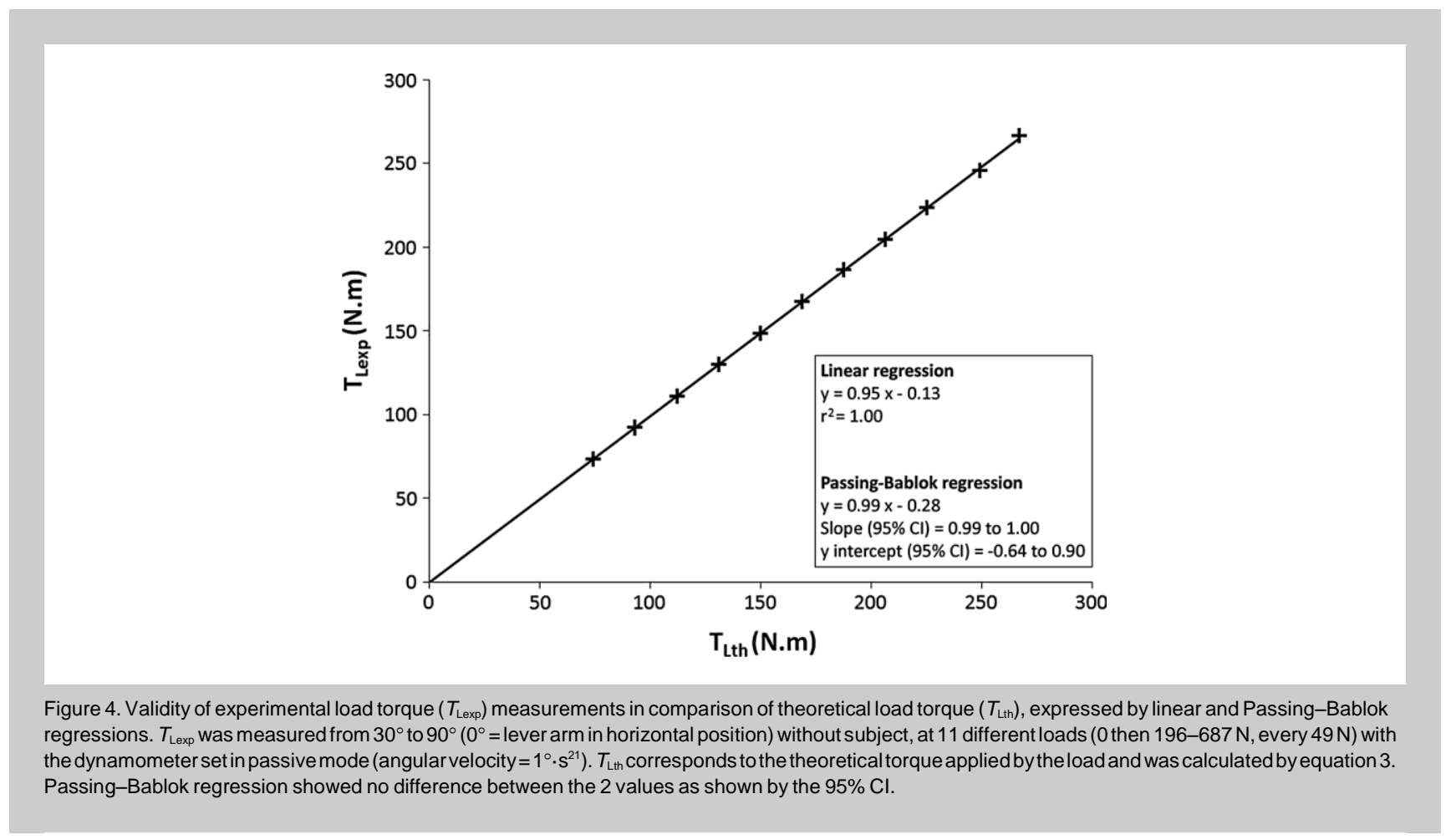


accordance with our hypothesis (see Mass moment of inertia calculation), this contribution was considered as negligible.

\section{Reproducibility of Work Calculation}

Intraclass correlation coefficient and SEM values demonstrated a satisfactory reproducibility for the total amount of external work (21,777 $6272 \mathrm{~J}$ vs. 21,786 $6269 \mathrm{~J})$ performed by the subjects in the IL eccentric set during the 2 test sessions $(S E M=38.3 \mathrm{~J}$; ICC $=0.98 ; \mathrm{CV}=2.3 \%)$.

\section{Discussion}

The aim of the present study was to test the validity of a simple new device allowing the acquisition of mechanical parameters during eccentric (or concentric) contractions against a constant external load. This device was developed on the same ergometer used in constant velocity movements, thus allowing the study of IL and IK movements in similar conditions. Reliability analyses showed satisfactory results which validated the mechanical measurements performed by this device.

Calculation of the amount of external work performed during IL eccentric exercise required the determination of the muscular torque produced by the subject. Consequently, each torque applied on the dynamometer attachment during eccentric exercise was determined (i.e., measured torque, load torque, leg torque, attachment torque, torque because of the mass moment of inertia). Experimental load torque measurements showed a friction effect. Nevertheless, the very low error between the experimental load torque and the theoretical load torque showed that this friction effect was considered by our methods. In addition, variations of torque because of the imperfect rolling contact between the wire and the metal piece were observed. Nevertheless, results showed that bias between experimental load torque and modeled load torque was equal to zero. Consequently, neither the friction effect nor the imperfect rolling contact between the wire and the half-circle metal piece had any effect on the external work calculation. Friction effect and imperfections of the material currently exist in weightlifting training conditions, thus increasing the interest of the use of this device with the goal of studying the effect of IL training.

Secondly, the mechanical load applied to the dynamometer attachment was almost perfectly constant and accurate, as demonstrated by the small SEM and CV, and the ICC value calculated between the experimental load torque and the theoretical load torque. These results were confirmed by the Passing - Bablok regression that showed no significant difference between the experimental load torque measurements and the theoretical load torque. The device developed in this study showed the validity of load torque measurements.

A major difference with IK movement is that angular velocity recorded in the IL mode is variable, thus implying changes in acceleration, notably at the start (extended knee angles) and the end (flexed knee angles) of the movement. Such mechanical characteristics could increase the contribution of the torque because of the moment of inertia to the total amount of external work performed in the IL mode. This contribution was consequently quantified and it reached less than 5\% (3.2\%). The calculation of amount of work did not take into account contribution of segmental moment of inertia of leg and attachment. However, the moment of inertia of leg and attachment was about $10 \%$ of the total moment of inertia, resulting in a contribution to the amount of external work less than $0.5 \%$. Therefore, this result confirmed the hypothesis that $J_{\text {Leg }}$ and $J_{\mathrm{a}}$ can be neglected to determine the amount of work. Calculation of external work based on muscular torque measurements showed a satisfactory reproducibility. Consequently, the validity and reproducibility analyses performed in passive and dynamic conditions support the validation of the simple device developed in the present study.

Study of IL eccentric exercise has previously been conducted to determine the level of muscular damages induced $(10,15,20)$, the muscle activation patterns (28), or to characterize the mechanical properties of musculoskeletal system (27) during such exercise. Numerous studies attempted to determine specifi force gains and physiological adaptations induced by an eccentric training in comparison to a concentric training period in the IL mode $(22,35,36)$. None of these studies precisely evaluated mechanical load by the quantifi tion of the amount of work performed and the angular velocity of movement. The present study allows the exact determination of this external load by the quantifi tion of external work. This is a first step before determining specifi effects of lengthening contractions in comparison of shortening contractions in IL mode in an acute session or after a training period.

\section{Practical Applications}

The device designed in this study allows the acquisition of mechanical parameters during eccentric exercise in IL mode on the same dynamometer used to usually perform eccentric contractions in the IK mode. This work enables the development of a standardization methodology of the IL and IK modes in eccentric contraction to compare their effects on the neuromuscular system. Such a study was previously tested in concentric exercise (31), showing differences in neural activation patterns in the IL and IK modes in shortening contractions as a function of angle (32). The mechanical differences that exist between the IL and IK modes in terms of torque and angular velocity suggest that specific structural and neural responses may likewise be observed in eccentric contractions $(4,9,21,28)$.

This device also allows acquisition of mechanical parameters during eccentric (or in concentric) contractions against a constant load. Such a device allows the study of constant external resistance exercise rather than dynamometersimulated isotonic exercise mode (30). Also, the movement is smoother and subjects have better control of their movement velocity. This device could be used to assess muscular force capacities (i.e., muscle strength, movement velocity, and muscle power as a function of joint angle) in eccentric contractions in the IL mode as commonly 
performed on an IK dynamometer. Furthermore, this device automatically pulls the load up to the starting position at a constant angular velocity. This technical aspect avoids any intervention of the investigator against heavy load levels (usually 100 - 140\% of 1RM in eccentric training).

To conclude, we developed a simple device that enables the acquisition of mechanical parameters during IL eccentric exercise. This study allows the determination of mechanical load by quantifi on of muscular torque, angle, angular velocity, and external work on the same ergometer used in the IK mode. The calculation of external work considered factors such as friction, material, and moment of inertia effects that potentially exist in IL training conditions (e.g., weightlifting exercises). This dynamometer development could be useful in future studies to develop a standardization methodology of eccentric and concentric trainings in the IL and IK modes. The mechanical characteristics inherent to each training mode suggest specifi response of the neuromuscular system and therefore that each mode would induce specifi strength gains and muscle and nervous adaptations. The present study would allow the comparison of the specifi responses and adaptations of the neuromuscular system induced by these exercise modes in the same conditions. Such a work could be of interest to coaches and clinicians who need to evaluate the work load or to better determine the objective of their training sessions or rehabilitation programs in which eccentric exercise is currently used.

\section{AcKnowledgments}

This study was supported by grants from the ' 'Ré gion des Pays de la Loire' ' and the ' 'Réseau Recherche et Sporten Pays de la Loire.' ' The authors are grateful to the subjects for having accepted to participate in this study and Philippe Sarazin for technical assistance (design of the device). They also thank Kris Knoblauch for his input. The results of the present study do not constitute endorsement of the product by the authors or the National Strength and Conditioning Association.

\section{REFERENCES}

1. Aagaard, P, Simonsen, EB, Trolle, M, Bangsbo, J, and Klausen, K. Isokinetic hamstring/quadriceps strength ratio: Influence from joint angular velocity, gravity correction and contraction mode. Acta Physiol Scand 154: 421 - 427, 1995.

2. Abernethy, P, Wilson, G, and Logan, P. Strength and power assessment. Issues, controversies and challenges. Sports Med 19: 401 - 417, 1995

3. Atkinson, $\mathrm{G}$ and Nevill, A. Typical error versus limits of agreement. Sports Med 30: 375 - 381, 2000

4. Babault, N, Pousson, M, Ballay, Y, and Van Hoecke, J. Activation of human quadriceps femoris during isometric, concentric, and eccentric contractions. J Appl Physiol 91: 2628 - 2634, 2001.

5. Bablok, W, Passing, H, Bender, R, and Schneider, B. A general regression procedure for method transformation. Application of linear regression procedures for method comparison studies in clinical chemistry, Part III. J Clin Chem Clin Biochem 26: 783 - 790, 1988.

6. Bland, JM and Altman, DG. Statistical methods for assessing agreement between two methods of clinical measurement. Lancet 1: 307 - 310, 1986

7. Bland, JM and Altman, DG. Comparing methods of measurement: Why plotting difference against standard method is misleading. Lancet 346: 1085 - 1087, 1995
8. Caruso, JF, Hamill, JL, Hernandez, DA, and Yamauchi, M. A comparison of isoload and isoinertial leg press training on bone and muscle outcomes. J Strength Cond Res 19:592 - 598, 2005.

9. Chino, K, Oda, T, Kurihara, T, Nagayoshi, T, Yoshikawa, K, Kanehisa, H, Fukunaga, T, Fukashiro, S, and Kawakami, Y. In vivo fascicle behavior of synergistic muscles in concentric and eccentric plantar flexions in humans. J Electromyogr Kinesiol 18: 79 - 88, 2008.

10. Chleboun, GS, Howell, JN, Conatser, RR, and Giesey, JJ. Relationship between muscle swelling and stiffness after eccentric exercise. Med Sci Sports Exerc 30: 529 - 535, 1998.

11. Croisier, JL, Foidart-Dessalle, M, Tinant, F, Crielaard, JM, and Forthomme, B. An isokinetic eccentric programme for the management of chronic lateral epicondylar tendinopathy. Br J Sports Med 41: 269 - 275, 2007.

12. Davies, CT and Barnes, C. Negative (eccentric) work. II. Physiological responses to walking uphill and downhill on a motor-driven treadmill. Ergonomics 15: 121 - 131, 1972.

13. Duclay, J and Martin, A. Evoked H-reflex and V-wave responses during maximal isometric, concentric, and eccentric muscle contraction. J Neurophysiol 94:3555 - 3562,2005.

14. Enoka, RM. Eccentric contractions require unique activation strategies by the nervous system. J Appl Physiol 81:2339 - 2346, 1996.

15. Folland, JP, Chong, J, Copeman, EM, and Jones, DA. Acute muscle damage as a stimulus for training-induced gains in strength. Med Sci Sports Exerc 33: 1200 - 1205, 2001.

16. Higbie, EJ, Cureton, KJ, Warren, GL III, and Prior, BM. Effects of concentric and eccentric training on muscle strength, cross-sectional area, and neural activation. J Appl Physiol 81:2173 - 2181, 1996.

17. Hopkins, WG. Measures of reliability in sports medicine and science. Sports Med 30: 1 - 15,2000

18. Hortobagyi, T, Hill, JP, Houmard, JA, Fraser, DD, Lambert, NJ, and Israel, RG. Adaptive responses to muscle lengthening and shortening in humans. J Appl Physiol 80: 765 - 772, 1996.

19. Housh, DJ, Housh, TJ, Weir, JP, Weir, LL, Evetovich, TK, and Donlin, PE. Effects of unilateral eccentric-only dynamic constant external resistance training on quadriceps femoris cross-sectional area. J Strength Cond Res 12:192 - 198,1998.

20. Howell, JN, Chleboun, G, and Conatser, R. Muscle stiffness, strength loss, swelling and soreness following exercise-induced injury in humans. J Physiol 464: 183 - 196, 1993.

21. Ishikawa, M and Komi, PV. The role of the stretch reflex in the gastrocnemius muscle during human locomotion at various speeds. J Appl Physiol 103: 1030 - 1036, 2007.

22. Kaminski, TW, Wabbersen, CV, and Murphy, RM. Concentric versus enhanced eccentric hamstring strength training: Clinical implications. J Athl Train 33: 216 - 221, 1998

23. Kellis, E and Baltzopoulos, V. Isokinetic eccentric exercise. Sports Med 19: 202 - 222, 1995.

24. Komi, PVand Buskirk, ER. Effect of eccentric and concentric muscle conditioning on tension and electrical activity of human muscle. Ergonomics 15: 417 - 434, 1972

25. Lieber, RL and Friden, J. Morphologic and mechanical basis of delayedonset muscle soreness. J Am Acad Orthop Surg 10: 67 - 73, 2002.

26. McHugh, MP. Recent advances in the understanding of the repeated bout effect: The protective effect against muscle damage from a single bout of eccentric exercise. Scand J Med Sci Sports 13: 88 - 97, 2003.

27. Murayama, M, Nosaka, K, Yoneda, T, and Minamitani, K. Changes in hardness of the human elbow flexor muscles after eccentric exercise. Eur J Appl Physiol 82:361 - 367,2000.

28. Nardone, A and Schieppati, M. Shift of activity from slow to fast muscle during voluntary lengthening contractions of the triceps surae muscles in humans. J Physiol 395:363 - 381, 1988.

29. Pensini, M, Martin, A, and Maffiuletti, NA. Central versus peripheral adaptations following eccentric resistance training. Int J Sports Med 23: $567-574,2002$. 
30. Purkayastha, S, Cramer, JT, Trowbridge, CA, Fincher, AL, and Marek, SM. Surface electromyographic amplitude-to-work ratios during isokinetic and isotonic muscle actions. J Athl Train 41: $314-320,2006$.

31. Remaud, A, Cornu, C, and Guevel, A. A methodologic approach for the comparison between dynamic contractions: Influences on the neuromuscular system. J Athl Train 40: 281 - 287, 2005.

32. Remaud, A, Cornu, C, and Guevel, A. Agonist muscle activity and antagonist muscle co-activity levels during standardized isotonic and isokinetic knee extensions. J Electromyogr Kinesiol 19: 449 - 458, 2009.

33. Schmitz, RJ and Westwood, KC. Knee extensor electromyographic activity-to-work ratio is greater with isotonic than isokinetic contractions. J Athl Train 36: 384 - 387, 2001.
34. Sleivert, GG and Wenger, HA. Reliability of measuring isometric and isokinetic peak torque, rate of torque development, integrated electromyography, and tibial nerve conduction velocity. Arch Phys Med Rehabil 75: 1315 - 1321, 1994.

35. Smith, RC and Rutherford, OM. The role of metabolites in strength training. I. A comparison of eccentric and concentric contractions. Eur J Appl Physiol Occup Physiol 71:332 - 336, 1995.

36. Vikne, H, Refsnes, PE, Ekmark, M, Medbo, JI, Gundersen, V, and Gundersen, K. Muscular performance after concentric and eccentric exercise in trained men. Med Sci Sports Exerc 38: 1770 - 1781, 2006.

37. Zatsiorsky, VM and Aktov, AV. Biomechanics of highly precise movements: The aiming process in air rifle shooting. J Biomech 23(Suppl 1): $35-41,1990$. 